\title{
El meme como práctica, expresión y manifestación artística, cultural y comunicacional de los jóvenes en la actualidad, caso Facultad de Comunicación Audiovisual del Politécnico Colombiano Jaime Isaza Cadavid
}

\author{
The meme as practice, expression and artistic, cultural and communicational \\ manifestation of young people today, case Faculty of Audiovisual Communication \\ of the Colombian Polytechnic Jaime Isaza Cadavid
}

Recibido: 12-07-2019 • Aprobado: 11-08-2020 • Página inicial: 155 - Página final: 174

\author{
John Fredy Vergara Vélez* \\ José Santiago Correa Cortés**
}

\begin{abstract}
Resumen: en el contexto colombiano, los estudiantes universitarios, como usuarios de redes sociales virtuales, consolidan un campo de construcción de procesos comunicativos multidireccionales, situándolos como interlocutores activos e individuos empoderados de sus propias construcciones comunicativas. El proyecto se orientó a la comprensión de las prácticas comunicacionales de los estudiantes de la Facultad de Comunicación Audiovisual frente a los usos, consumos y producción de memes de internet. El proyecto contempló la necesidad de comprender las prácticas comunicacionales de los jóvenes, desde las formas discursivas del Meme como unidad de significado sociocultural, apropiados y difundidos por ellos, desde el uso de las redes sociales virtuales y así mismo indagar en las formas figurativas y alcances de estas unidades de sentido en diferentes ámbitos. Utilizando técnicas interactivas como el grupo focal, talleres de cartografía y entrevistas, los estudiantes realizan aproximaciones a la construcción de significaciones socioculturales mediante el meme y las estrategias de viralización de contenidos digitales. Como resultado parcial de esta indagación, se reconocen cómo los sujetos/objetos de investigación encuentran en el meme una herramienta para construir relaciones sociales, como método para comunicarse con el otro, informarse y divertirse. Como poco conocen su historia y su estructura, apenas se hacen una idea.
\end{abstract}

Palabras clave: meme; sujeto joven; educomunicación; prácticas comunicacionales; ambientes virtuales; prosumidores.

\begin{abstract}
In the Colombian context, university students as users of virtual social networks consolidate a field of construction of multidirectional communicative processes, situating them as active interlocutors and empowered individuals of their own communicative constructions. The project was oriented to the understanding of the communication practices of the students of the Faculty of Audiovisual Communication in front of the uses, consumption and production of Internet memes. The project contemplated the need to understand the communicational practices of young people, from the discursive forms of the Meme as a unit of sociocultural meaning, appropriate and disseminated by them, from the use of virtual social networks and also investigate the figurative forms and scopes of these units of meaning in different areas. Using interactive techniques such as the focus group, cartography workshops and interviews, the students make approximations to the construction of sociocultural meanings through the meme and viralization strategies of digital content. As a partial result of this inquiry, they recognize that the subjects / objects of research find in the meme a tool to build social relationships, as a method to communicate with the other, to inform oneself and to have fun. Although, little is known about their history and structure, they hardly get an idea.
\end{abstract}

Keywords: Meme; young subject; educommunication; communicational practices; virtual environments; prosumers.

JEL: Z19

\footnotetext{
* Catedrático Facultad de Comunicación Audiovisual, Politécnico Colombiano Jaime Isaza Cadavid, Colombia. johnvergara@elpoli.edu.co ORCID: https://orcid.org/0000-0002-6403-9532

** Docente vinculado Facultad de Comunicación Audiovisual, Politécnico Colombiano Jaime Isaza Cadavid, Colombia. josecorrea@elpoli.edu.co

ORCID: https://orcid.org/0000-0001-9026-0102
} 


\title{
Contexto vergasa,,$y$ yorras,
}

\section{O meme como prática, expressão e manifestação artístico, cultural e comunicacional dos jovens no presente, case Faculdade de Comunicação Audiovisual do Politécnico Colombiano Jaime Isaza Cadavid}

\begin{abstract}
Resumo: no contexto colombiano, os universitários, como usuários das redes sociais virtuais, consolidam um campo de construção de processos comunicativos multidirecionais, posicionando-os como interlocutores ativos e indivíduos empoderados de suas próprias construções comunicativas. O projeto teve como objetivo compreender as práticas de comunicação dos alunos da Faculdade de Comunicação Audiovisual face aos usos, consumo e produção de memes da internet. O projeto contemplou a necessidade de compreender as práticas comunicacionais dos jovens, a partir das formas discursivas do Meme como unidade de sentido sociocultural, apropriada e disseminada por eles, a partir do uso das redes sociais virtuais e também de investigar as formas figurativas e abrangência. dessas unidades de significado em diferentes áreas. Utilizando técnicas interativas como grupo focal, oficinas de mapeamento e entrevistas, os alunos fazem abordagens para a construção de significados socioculturais por meio do meme e das estratégias de viralização do conteúdo digital. Como resultado parcial desta investigação, reconhece-se como os sujeitos / objetos de pesquisa encontram no meme uma ferramenta para construir relações sociais, como um método para comunicar-se com o outro, informar-se e divertir-se. Por pouco conhecerem sua história e estrutura, dificilmente têm uma ideia.
\end{abstract}

Palavras-chave: meme; sujeito jovem; educomunicação; práticas de comunicação; ambientes virtuais; prosumers. 


\section{Introducción}

La noción de práctica puede ser entendida como conjuntos de hábitos que asumen los individuos y se manifiestan en acciones y actividades concretas, en diversos momentos o situaciones desde lo individual y colectivo.

En este sentido, las prácticas y expresiones juveniles se revelan en diversidad de sentidos, donde las enunciaciones artisticoculturales y comunicacionales constituyen más que lugares y cosas; componen un entramado complejo de actuaciones que otorgan sentido y significado a las producciones de las y los jóvenes en la actualidad.

En el contexto Colombiano, son cada vez más los jóvenes que hacen uso de las TIC y desde luego de las redes sociales virtuales, consolidando así un campo de construcción de procesos comunicativos multidireccionales, situando así a los jóvenes como interlocutores activos e individuos empoderados de sus propias construcciones comunicativas, es decir, los consumos de información se dan en diversos ámbitos y momentos, pero el vivo reflejo de la producción comunicativa configura la comunicación ahora desde la lógica de un sujeto que es prosumidor.

Una de las prácticas comunicacionales recurrentes en los jóvenes hoy en día es el acto del prosumo de memes. En la heterogeneidad de informaciones y contenidos que se alojan y se difunden masivamente en las redes sociales virtuales, el meme aparece como una figura discursiva dotada de significados, cuyo efecto de masificación se encuentra en las lógicas complejas que operan en la viralización de la información y, desde luego, en las múltiples lecturas de los usuarios-sujetos comunicativos.

Bajo este escenario, se configura una trama de sentidos de las prácticas comunicacionales de los jóvenes, en función del uso, consumo y producción de memes; unidades de significado, que si bien aparecen tácitos en imágenes, videos y otras composiciones visuales digitales que ellos comparten, adquieren alcance dentro del contexto social y cultural en los que aparecen y son apropiados por los jóvenes-sujetos comunicativos, pero más allá del sentido de apropiación cultural y social que tienen las juventudes actuales, el meme, en sí mismo, es un portador y dispositivo configurativo de la cultura y de lo social.

De este modo, el proyecto ha contemplado la necesidad de comprender las prácticas comunicacionales de los jóvenes, específicamente desde las formas 


\section{Contexto vergasa,,$y$ yorras,}

discursivas del meme como unidad de significado sociocultural, que es apropiado y difundido por ellos desde el uso de las redes sociales virtuales y, así mismo, indagar por las formas figurativas y alcances de estas unidades de sentido en el ámbito cultural, social, educativo e informativo.

\section{Planteamiento del fenómeno de investigación}

En el escenario de las prácticas artisticoculturales y comunicacionales de los jóvenes, estas actúan en función de las expresiones y manifestaciones de las subjetividades juveniles de una forma individual y colectiva. Si bien, las expresividades que construyen los jóvenes en la actualidad constituyen en esencia la manifestación de las subjetividades de los mismos, estas expresiones adquieren, en ocasiones, la forma de representaciones concretas que acentúan los significados que otorgan ellos al mundo que los rodea, así como las capacidades creativas y expresivas, propias de un marco de manifestación sociocultural y comunicacional.

Respecto a las prácticas y expresiones comunicacionales de los jóvenes en la actualidad, las TIC y las redes sociales virtuales consolidan así una serie de espacios de enunciación de los jóvenes. Bajo esta lógica, los procesos comunicativos que construyen, atienden a la noción de prácticas comunicacionales, asumiendo tanto roles activos de ellos mismos en condición de sujetos comunicativos-prosumidores en el contexto de la comunicación digital, pero ante todo entendiendo los procesos de comunicación de los jóvenes como configuraciones de sentidos y significados de lo cultural, lo social, y desde luego de la comunicación pensada, sentida y vivida desde sus propias lógicas.

Con relación a las prácticas comunicacionales, es cada vez más recurrente la producción de contenidos e informaciones de variados matices estéticos y expresiones discursivas reflejadas en híbridas y sofisticadas piezas comunicativas alojadas en las redes sociales virtuales.

Si bien, se asumen las prácticas comunicacionales como acciones comunicativas en concreto que realizan los jóvenes en función de la expresión y manifestación de múltiples sentidos, la comunicación digital se constituye en el escenario de despliegue de estas acciones, bien sea en su forma individual o también en su manifestación colectiva.

Tal es el caso de las informaciones y contenidos que consumen los usuariosjóvenes de las redes sociales: fotomontajes, animaciones, sketches, gifs, entre 
otras piezas. Estos constituyen variadas formas expresivas que actúan en sinergia con los procesos de significación, tanto de quienes las producen como de quienes las consumen; sin embargo, este proceso de consumo y producción, entendido desde las lógicas de la figura del prosumer, adquiere forma y sentido en la medida en que las informaciones y contenidos se difunden de manera masiva entre los usuarios de las redes sociales.

Los jóvenes universitarios aluden a diversidad de consumos, usos y producciones de contenidos e informaciones, cuyas funciones expresivas se articulan a variadas y novedosas formas discursivas que poseen un elemento en común: la capacidad de compartir rasgos; esto es, la capacidad de viralización digital de dichas expresividades. A propósito de esta dinámica comunicativa, aparece el concepto de meme, el cual propone "Dawkins $(1988 ; 1979)$ para referirse a las instrucciones culturales que forman el sentido social de las épocas. Desde una analogía con el concepto de genes, y su aplicación a la evolución biológica, se puede apreciar que los memes son las instrucciones "genéticas" para la acción y la comunicación social (Santibáñez, 2001, p.65).

En este sentido, se establece una relación inicial entre el meme de internet y la biología, desde la noción de agrupación de un conjunto de propiedades y cualidades del meme que se articulan en dimensiones culturales. Y si bien, para Santibáñez (2001) la semejanza que se propone con la biología indica la existencia de elementos re-organizados entre sí que definen las características de comportamiento cultural, las anteriores consideraciones conllevan a comprender que la cultura no se entiende como un conjunto de formas de conducta, sino como información que especifica dichas formas en los comportamientos culturales de los individuos.

En la actualidad, es cada vez más creciente el efecto viral de informaciones y diferentes contenidos en las redes sociales. Es así como aparece, en el panorama de la comunicación digital, el meme como unidad de sentido y significado social y cultural, transmitiendo ambos, y cada vez contempla una mayor complejidad, lo que significa que un "(...) meme posee las características propias de todo proceso evolutivo: fecundidad, longevidad y fidelidad en la replicación" (como se citó en Dawkins, 1985). A su vez, existe un amplio campo de variación, los memes se replican a sí mismos por mecanismos de imitación y transmisión de cerebro a cerebro. La producción estética, discursiva y comunicativa de estos jóvenes toma forma en los memes y contenidos virales, teniendo como escenario de enunciación las redes sociales $\mathrm{y}$, desde luego, los contextos sociales y culturales en los que ellos despliegan sus actuaciones como sujetos. 


\section{Contexto vegara a, y yorras,}

Razón por la que los memes se constituyen como medio de expresión que logran a través de su propagación premeditada o no, transmitir ideas y concepciones sociales, culturales, políticas, entre otros; también poseen la capacidad de generar importantes cambios en las percepciones de los individuos, acentuándose en otros escenarios de actuación.

El imeme es una forma de comunicación visual que puede manifestarse en diversos formatos: una imagen, un GIF animado o incluso un video. La mayoría de ellos son simples, de baja resolución y de estilo mundano. "La belleza y el realismo no son prioridad a la hora de crear un meme, el enfoque está en el mensaje. A las imágenes se les añade texto, sonido e incluso otras imágenes para exhaltar las cualidades virales del meme" (como se citó en Gómez, 2013; 2014, p.4).

Si bien, los memes constituyen un complejo lenguaje de sentido, en donde se reflejan diversidad de representaciones de los fenómenos sociales y culturales en que se ven envueltos; estos también se conciben últimamente como medio político e ideológico que se adhieren a una opinión pública que se configura de manera reiterada en el escenario de las redes sociales.

Por ello, es ineludible dimensionar las prácticas comunicativas de los jóvenes desde los memes como unidades de sentido y significado y cuya función discursiva se consolida a través de múltiples configuraciones narrativas; todo esto, en sinergia con las competencias sociales, culturales y políticas que construyen los sujetos-jóvenes, a través de sus acciones comunicacionales, específicamente en y desde la lógica de los contenidos e informaciones que se comportan como virus propagados en las redes sociales, es decir, desde el uso, consumo y producción de una comunicación memética.

\section{Objetivos}

Este artículo resultado de investigación tiene como objeto de estudio las prácticas comunicacionales juveniles, está centrada en la indagación frente a los usos, consumos y producción de memes en internet de los jóvenes estudiantes de la Facultad de Comunicación Audiovisual del Politécnico Colombiano Jaime Isaza Cadavid.

Objetivo que se hizo alcanzable a través de la descripción de las prácticas comunicacionales recurrentes en las redes sociales de los estudiantes de la Facultad de Comunicación Audiovisual. 
Por otra parte, se determinaron las características semióticas, estéticas y narrativas de los contenidos digitales de carácter masivo, viral y transversal, analizando los usos, consumos y producción de memes en internet de los estudiantes de la Facultad de Comunicación Audiovisual.

\section{Metodología}

El proyecto contempló como estrategia metodológica un enfoque descriptivo-interpretativo, cuya finalidad fue la comprensión de las prácticas comunicacionales de los estudiantes de la Facultad de Comunicación Audiovisual frente a los usos, consumos y producción de memes en internet.

Para ello, y en función de la perspectiva cualitativa de este estudio, se emplearon diversas técnicas de investigación, así como procedimientos para la recolección de información.

También se hizo énfasis en la posibilidad experimental que ofrecen los diseños cualitativos de investigación. En este sentido, la muestra de participantes de la investigación, se constituyó por cuatro estudiantes miembros del semillero de investigación en comunicación y viralización de contenidos digitales (INCODI) que pertenecen a los semestres cuarto, quinto y sexto del programa de Comunicación Audiovisual del Politécnico Colombiano Jaime Isaza Cadavid; y doce estudiantes de la asignatura eventos online del programa de Tecnología en Organización de Eventos de la misma institución, y a quienes se les indagó a través de la realización de actividades de conceptualización y creación de memes, así como la aplicación de otros instrumentos para la recolección de información para el estudio.

A continuación, se detallan los procedimientos de recolección de información de acuerdo a los objetivos específicos del proyecto:

- Entrevistas estructuradas y semiestructuradas a los estudiantes de la Facultad de Comunicación Audiovisual, frente a las prácticas comunicacionales y sobre los usos, consumos y producción de contenidos masivos y virales de internet y sus redes sociales.

- Grupos focales frente a los alcances y limitaciones de los contenidos e informaciones virales (memes) en internet y las redes sociales.

- Talleres de discusión-reflexión frente a los usos, consumos y producción de contenidos diversos desde el fenómeno de la comunicación digital. 


\section{Resultados}

Para los estudiantes de la Facultad de Comunicación Audiovisual del Politécnico Colombiano Jaime Isaza Cadavid, sus procesos de subjetivación, así como los trayectos que construyen en las configuraciones como sujetoscomunicativos, se estructuran no solamente en expresiones y manifestaciones artístico-culturales; desde luego, las interacciones sociales, constituyen el eje de articulación de los procesos de comunicación y educación en el escenario de la comunicación digital.

En efecto, la comunicación adquiere varios sentidos en este panorama. Para estos jóvenes, la comunicación se produce en las interacciones con el otro, a partir de las mediaciones con los dispositivos tecnológicos, los espacios virtuales y las redes sociales. Todo ello conlleva a la comprensión de la existencia de prácticas concretas de la comunicación. Partiendo de la noción de prácticas, esta se comprende desde la idea del habitus que para Bourdieu es “(...) el proceso por el que lo social se interioriza en los individuos y logra que las estructuras objetivas concuerden con las subjetivas" (1990, p.26).

"El habitus, generado por las estructuras objetivas, genera a su vez las prácticas individuales, da a la conducta esquemas básicos de percepción, pensamiento y acción" (Bourdieu, 1990, pp.26-27). Lo que indica que el habitus se traduce en acciones concretas e interiorizadas en cada uno de estos jóvenes, partiendo de estructuras macrosociales generales, pero configurándose en formas específicas en cada uno de ellos en su condición de sujetos. Por lo tanto, las prácticas que realizan estos chicos y chicas en función de la comunicación, se cimentan específicamente en las bases del consumo de información y medios, así como en la producción de contenidos de variadas temáticas (prosumos) y en la producción de significaciones diversas en relación a sus pensamientos, conductas y consolidación de roles dentro del ecosistema comunicativo digital.
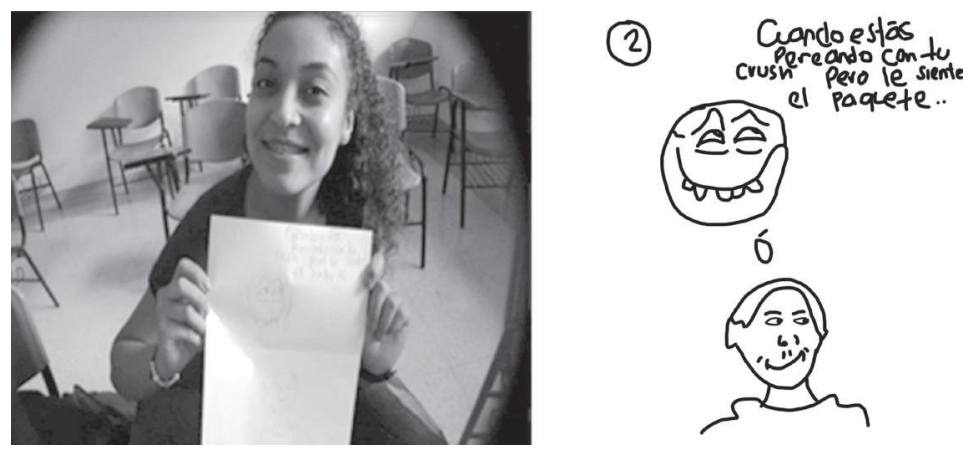

Figura 1. Grupos focales y talleres de elaboración de memes con los estudiantes de la Facultad de Comunicación Audiovisual del Politécnico Colombiano JIC. 
Si bien, para ellos la televisión e internet siguen ocupando lugares privilegiados en cuanto a sus usos; factores como entretenerse, informarse y educarse constituyen funciones directas, que ellos mismos otorgan a los massmedia y que obedecen a la oferta de contenidos y programaciones que se les ofrece. No obstante, tanto la utilización de la televisión e internet y sus empleos para obtener diversas gratificaciones (informarse, entretenerse y educarse) siguen manteniendo un orden vigente dentro de la lógica operativa de los medios masivos de comunicación en la actualidad. En efecto, es imprescindible comprender que los “(...) medios de comunicación de masas presentan constantemente modos de vida a los que, según se supone, todos deben aspirar” (Beriain, 1996, p.251).

Los usos y consumos de los medios de comunicación que hacen estos chicos y chicas, se articulan desde la lógica de una economía de mercado y de producción masiva y, por ende, las significaciones frente a los mensajes y contenidos están sujetas a incentivos de tipo emocional, incluso ideológico que inciden en sus percepciones, hábitos y comportamientos. Para Beriain (1996) “(...) el desarrollo de los medios de comunicación, particularmente la comunicación electrónica, la interpenetración del autodesarrollo y de los sistemas sociales, incluyendo sistemas globales, se hace más pronunciada" (p.37). ${ }^{1}$

En este sentido, la comunicación de los medios masivos concentra sus funciones en las dinámicas de la economía actual; así, el consumo y recepción de las informaciones para estos chicos y chicas adquieren significados cada vez más tácitos y legítimos en sus formas de producción de sentido social y cultural. Para Martín-Barbero (1992).

(...) esta nueva perspectiva industria cultural y comunicaciones masivas son el nombre de los nuevos procesos de producción y circulación de la cultura, que corresponden no sólo a innovaciones tecnológicas sino a nuevas formas de la sensibilidad y a nuevos tipos de disfrute y apropiación (p.8). ${ }^{2}$

\footnotetext{
1 "Yo diría que la televisión es un medio de comunicación masivo, entonces lo que hace la televisión es como darnos unos mensajes y a veces son como muy subliminales, por ejemplo, a mí me parece muy cómico y es lo que colocan en la televisión; por ejemplo, jel programa para mayor de 12 años!, entonces yo digo que lo colocan por la simbología. Por ejemplo, los niños menores de 12 años o yo que estudiaba teatro, nos enseñaban mucho lo que es los símbolos y con cualquier cosita uno puede relacionar muchas cosas, uno puede colocar un círculo, entonces la imaginación se le vuela a uno" (fuente estudiante grupo focal).

2 "Me gustan demasiado las series y creo que uno aprende cosas porque hay veces las series, así no las crea, hay cosas que son muy reales y uno puede aprender por medio de las películas, las series y todo eso" (fuente estudiante grupo focal).
} 


\section{Contexto vegara, a, ycomea,}

En consecuencia, estos jóvenes realizan varias acciones frente a los referentes visuales que ofrecen los medios de comunicación y su amplia oferta de programación y contenidos. El acto de seguir a una personalidad famosa, investigar sus vidas y quehaceres profesionales y valorar las creaciones y producciones de las figuras mediáticas, configuran así un conjunto de actuaciones que estos chicos y chicas realizan constantemente, pues se presenta una doble vía entre el consumo y producción de los mensajes.

El consumo de programación y contenidos de los medios masivos de comunicación, se articula con la utilización de las redes sociales virtuales, cuyas interacciones se dan, por un lado, en el momento en el que se presentan los consumos y usos psicológicos e ideológicos de la información y, por otro, en las posibilidades de generar contenidos, a partir de las réplicas de los mensajes, es decir, a través de la acción de compartir la información existente, teniendo la posibilidad de modificar el contenido de los mensajes y difundiéndolos en tiempo posterior; cualidades que ofrecen las redes sociales, como por ejemplo WhastApp, Facebook e Instagram. ${ }^{3}$

Los usos, consumos y producción de información que se vislumbran como prácticas comunicativas de estos jóvenes, se comprenden en el complejo entramado de la comunicación masiva y las industrias culturales. Para MartínBarbero (1992) la dicotomía entre ambas presupone el “(...) nombre de los nuevos procesos de producción y circulación de la cultura, que corresponden no sólo a innovaciones tecnológicas sino a nuevas formas de la sensibilidad y a nuevos tipos de disfrute y apropiación" (p.8).

Precisamente, ellos generan constantemente procesos comunicativos mediados por las tecnologías digitales y los consumos de nuevos y variados formatos, estilos y discursos. A su vez, las redes sociales constituyen escenarios de sociabilidad que sugieren nuevas formas de juntarse y de excluirse, de reconocerse y desconocerse y que adquieren espesor social y relevancia cognitiva lo que pasa en y por los medios y las nuevas tecnologías de comunicación (Martín-Barbero, 1992, p.9). ${ }^{4}$

\footnotetext{
3 "Yo opino que los jóvenes cuando ven, se ven representados con las personas que hacen esos videos, los youtubers, por ejemplo. Es como cualquiera de nosotros, tomar una cámara y expresar todo lo que nosotros pensamos y hacen cosas que a la gente como a nosotros nos gusta" (fuente estudiante grupo focal).

4 "Por ejemplo en las películas que hay en Netflix, si hay una película ahí y puede buscar en internet la película, en Facebook y eso y hay miles de personas que comparten la misma idea y les gusta lo que a usted les gusta, entonces usted forma parte de ese grupo (fuente estudiante grupo focal)".
} 
Tanto las interacciones sociales de estos jóvenes como los procesos comunicativos soportados en prácticas comunicacionales en el escenario de las tecnologías digitales (el universo cultural inmediato, así como sus propias configuraciones y manifestaciones culturales) están anudadas a las lógicas de una economía global incidente en las dinámicas de socialización juvenil, en las construcciones de la cultura y, desde luego, en las dinámicas comunicativas, ya no mediadas por las tecnologías digitales, sino vinculadas a estas: las comunicaciones de estos chicos y chicas dependen significativamente de las posibilidades del medio, es decir, de las herramientas tecnológicas de último avance tecnológico y de los dispositivos móviles más sofisticados.

Sin embargo, las prácticas comunicacionales de estos chicos y chicas adquieren mayor espesor en relación al lenguaje, cuyas transformaciones se dan en la medida en que ellos emplean el medio tecnológico, en función de la interacción social y el acercamiento al otro. Para Habermas (1987) el lenguaje “(...) actúa aquí como medio, no del entendimiento y de la transmisión de saber cultural, sino de la socialización y de la integración social" (p.40). Entonces desde el punto de vista estructural de la comunicación, el lenguaje mismo no solamente es funcional en el empleo de sus estructuras lingüísticas y sistemas sígnicos, sino que depende de los artefactos y dispositivos tecnológicos empleados y en la capacidad de interconexión que ofrecen los celulares y dispositivos móviles. ${ }^{5}$

En consecuencia, los protagonismos de estos jóvenes interpelan al acto de entenderse e interactuar, a través de la conexión virtual con otros jóvenes en cuestiones comunes. Las redes sociales y las multiplicidades de informaciones y mensajes que alberga internet, y las posibilidades interactivas que proponen diversidad de espacios y entornos virtuales, constituyen así un microcosmos social, cultural y comunicativo, donde las significaciones de ellos mismos como sujetos-jóvenes establecen horizontes de sentidos en sus prácticas comunicativas y, por ende, en la autodefinición de sí mismos. En este sentido, Habermas señala que los "(...) sujetos que actúan comunicativamente se ven ante la tarea de encontrar para su situación de acción una definición común y de entenderse, dentro de ese marco de interpretación, sobre temas y sobre planes de acción" $\left(1987\right.$, p.313). ${ }^{6}$

\footnotetext{
5 "Nosotros tenemos que estar conectados. Para nosotros un celular sin internet no sirve; y si no hay una forma de un WiFi en una casa o en un lugar, hay que tener datos para poder andar por ahí y para sentirse en confianza. Ya la plata de nosotros ya no es tanto para gastar en las cosas materiales sino para datos (fuente estudiante grupo focal)".

6 "Yo creo que internet en forma de grupo funciona. Yo he visto que los grupos de WhatsApp por ahí hablan así, por ahí hablan las personas, o sea que también ayudan al desarrollo personal, pero, por ejemplo, Instagram, donde comparten fotos, aunque uno no crea esas fotos que uno ve a uno le influyen en el pensamiento" (fuente estudiante grupo focal).
} 


\section{Contexto vergasa, y corras,}

Así, entonces, asumiendo la comunicación como procesos de acción de los sujetos, las prácticas comunicacionales que realizan estos jóvenes (Habermas 1987) se soportan en la relación entre cultura, sociedad y personalidad como componentes de la vida simbólicamente estructurada.

De este modo, internet, y específicamente los dispositivos móviles y las redes sociales, "(...) se ha convertido en medio de autoexpresión, símbolo de estatus y forma de proyección de la identidad” (Muñoz, 2008, p.8). ${ }^{7}$

En efecto, la sociedad actual en la que viven y están inmersos estos jóvenes, así como las dinámicas del poder y las lógicas del mercado, pasan de manera cada vez más reiterada por las transformaciones tecnológicas, por nuevas estructuras narrativas y discursos que, de cierta manera, reorganizan los modos en los que se relacionan los sujetos-jóvenes con la cultura, desde la producción, circulación y consumos de las informaciones (textos, imágenes, objetos, etc.).

En esencia, la producción de la cultura que hacen estos chicos y chicas se entiende en esta dimensión, es decir, es la puesta en marcha de acciones individuales y colectivas, donde la cultura se configura desde sus procesos comunicativos. Atender a las prácticas, a los hábitos y a los usos, puede comprenderse en las posibilidades que ellos tienen para acercarse al conocimiento y reconocerse en la cultura. Para Urresti, Linne, y Basile, esta dinámica permite entender “(...) sus tensiones y contradicciones, de sus expresiones y sus silencios, es decir, de sus estrategias comunicativas a través de las cuales se manifiestan las mediaciones culturales" (2015, p.35).

En consecuencia, las tecnologías suponen un cierto consumo de bienes, dispositivos y servicios específicos, pero también supone una constante actividad de interacción a partir de la utilización y la posibilidad de producir nuevos contenidos y herramientas, que permiten procesos de consumo, de producción y creatividad. Según Urresti et al., (2015), los procesos de recepción, consumo y producción, así como la reactivación de nuevos roles del actor comunicativo,

\footnotetext{
7 "Yo podría aportar que eso no es del todo malo, yo por ejemplo mantengo, no muy frecuente, más o menos, juegos en línea y yo he conocido muchas personas por Internet y yo conocí unos amigos de Chile y Ecuador y pues es bueno eso como le ayuda a uno como a expandir lo que uno conoce y a quien conoce y pues ellos han venido a Colombia, no es que sólo es por ahí, sino que es bueno también en parte porque lo ayuda a conocer más personas, pues es parte positivo" (fuente estudiante grupo focal).
} 
circulan y se utilizan, acrecentándose y diversificándose en nuevos contenidos que aumentan progresivamente. ${ }^{8}$

En esencia, las actuaciones y expresiones comunicativas de los jóvenes, en el escenario de las redes sociales, específicamente en la creación y viralización de contenidos digitales como los memes en internet, indican precisamente que "un meme de internet es un segmento de la cultura que se representa de manera cotidiana a modo de chiste y que al ir transmitiéndose adquiere influencia" (González, 2017, p.2).

"Los usuarios están allí para recordarnos que los procesos de comunicación digital son procesos eminentemente sociales y se desarrollan en el territorio que plantean las necesidades de los sujetos en los distintos momentos de su vida". (Urresti et al., 2015, p.36). Para estos chicos y chicas, las redes sociales constituyen escenarios de interlocución y encuentro con otros jóvenes; sus procesos de comunicación como bien se ha mencionado, están soportados por las tecnologías digitales y el uso del celular y cuyas informaciones reproducidas y coproducidas, dadas las versatilidades y posibilidades de las aplicaciones virtuales y digitales, consolidan así todo un ecosistema comunicacional-digital, en donde se exploran y consolidan sus creatividades, expresiones y pensamientos. ${ }^{9}$

\section{El meme visto y producido desde los sujetos/objetos de la investigación}

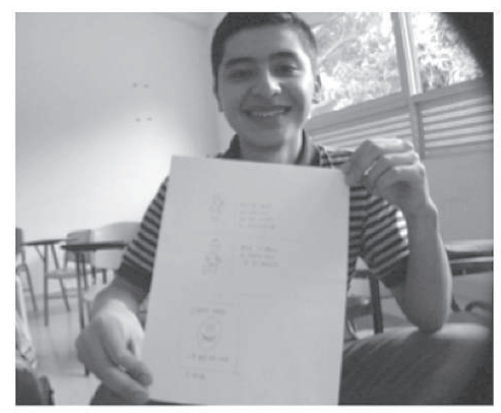

Figura 2. Grupos focales y talleres de elaboración de memes con los estudiantes de la Facultad de Comunicación Audiovisual del Politécnico Colombiano JIC.

\footnotetext{
8 "Ellos ya no se mandan tantas palabras propias, sino memes que ellos ven por ahí, cosas graciosas, entonces las mandan y eso se vuelve en cadenas; yo he visto que aquí que en cada curso hay un grupo de WhatsApp y hay una cadena; ellos forman un grupo cerrado, entonces, por ejemplo, el grupo de investigación, todos tienen su celular, todos se comunican en el grupo de WhatsApp. Ellos se mandan también muchos memes, por ejemplo, dicen: ¡Ve esto está muy gracioso!, entonces de esa forma, ellos entran a la política, entran al conocimiento del país, entran a una nueva forma de humor más gráfico; ya no es contando chistes, sino a través de los memes que ellos empiezan a compartir el humor y otras cosas" (fuente docente grupo focal).

9 "Yo digo que cuando una persona normal así como nosotros sube videos a internet, también ayuda a que otras personas vean el pensamiento de uno" (fuente estudiante grupo focal).
} 


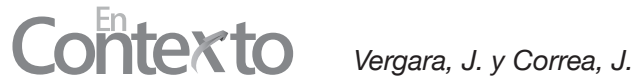

Con el ánimo de escuchar desde la voz del estudiante y visibilizar los resultados y percepciones que se derivan del proyecto, se comparte el análisis realizado por dos estudiantes integrantes del proyecto de investigación.

Este es un análisis con algunas conclusiones parciales de la actividad de la determinación de las características semióticas, estéticas y narrativas de los contenidos digitales de carácter masivo y viral.

Si bien, ya hemos tocado algunos conceptos y términos sobre el meme en internet, no damos cuenta que no todos tienen claridad sobre el significado y origen del mismo.

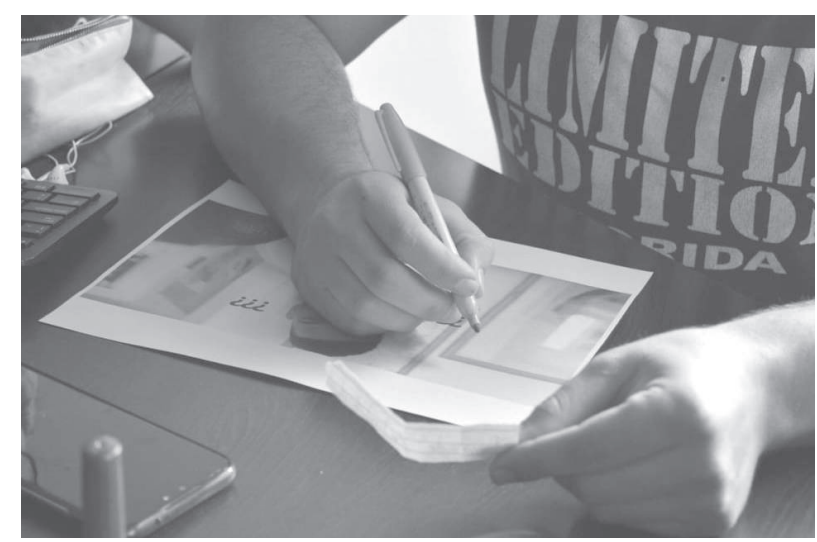

Figura 3. Grupos focales y talleres de elaboración de memes con los estudiantes de la Facultad de Comunicación Audiovisual del Politécnico Colombiano JIC.

Observamos que la contextualización que tienen los estudiantes de tercer semestre de Comunicación Audiovisual, con lo que llamamos meme en internet, es más bien una relación de socialización, un método para comunicarse con el otro, informarse y divertirse. Sin embargo, no conocen su historia y de su estructura apenas se hacen una idea.

En el transcurso de las intervenciones con el grupo focal, nos encontramos con diversas opiniones del uso del meme y de alguna manera todos concuerdan con que el meme hace parte de una mera imagen que divierte y que hace criticas a situaciones de la cotidianidad, de la política y de la sociedad. Esto nos muestra que el meme ha evolucionado y ahora algunos memes en internet cumplen con la intención de generar un pensamiento crítico desde el humor, la burla y el sarcasmo. 
Para estos participantes, la estética es fundamental para el gusto y la viralización del meme, no les gusta que las imágenes/videos/textos estén acompañados de muchos colores, muchas figuras ni muchas imágenes en una sola. Disfrutan que desde lo sencillo visualmente se haga un meme divertido y de buen contenido y asi se pueda replicar una y otra vez.

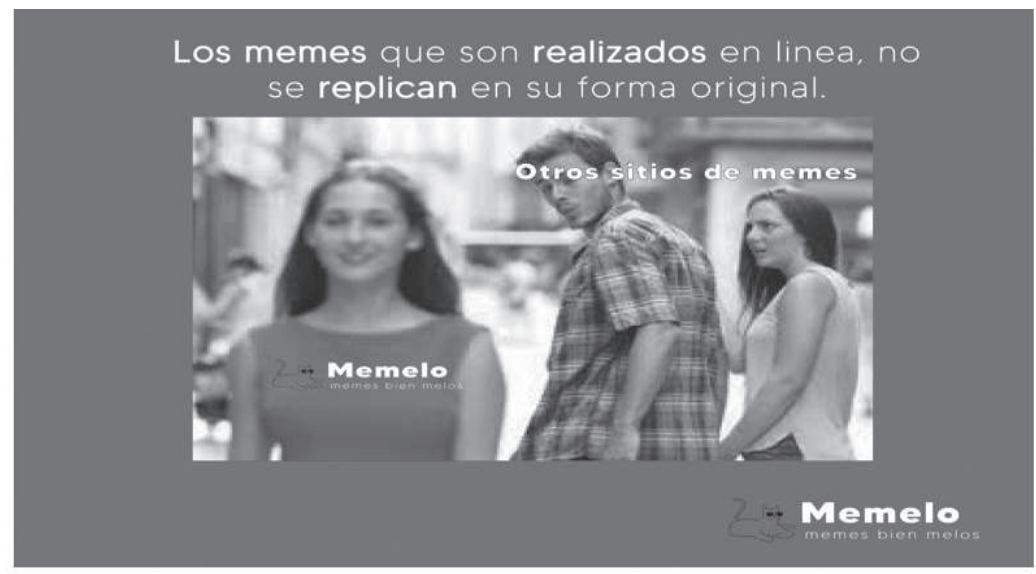

Figura 4. Meme elaborado por el semillero de investigación INCODI. Facebook.

El meme funciona, desde la intención semiótica, perfectamente con la teoría de Saussure, según los datos recolectados en este grupo focal. Pues los estudiantes siempre le dan un significado al significante y esto conlleva a la transculturización de la mera imagen en diferentes lugares del mundo. Muy bien lo decía uno de los estudiantes: no es lo mismo ver un meme de Rusia, y entenderlo igual, que uno de Colombia.

Los participantes manifestaron a través de una pregunta realizada por las moderadoras, que se han enterado de muchas noticias importantes del país mediante los memes. Gracias a la viralización de este y al alcance que tiene las redes sociales se inundan de esa noticia que es tendencia y el meme sirve como medio de información noticioso y esto los motiva a investigar, por fuentes confiables, como prensa digital, qué es lo que sucede en ese instante. 


\section{Contexto vergasa, y corras,}

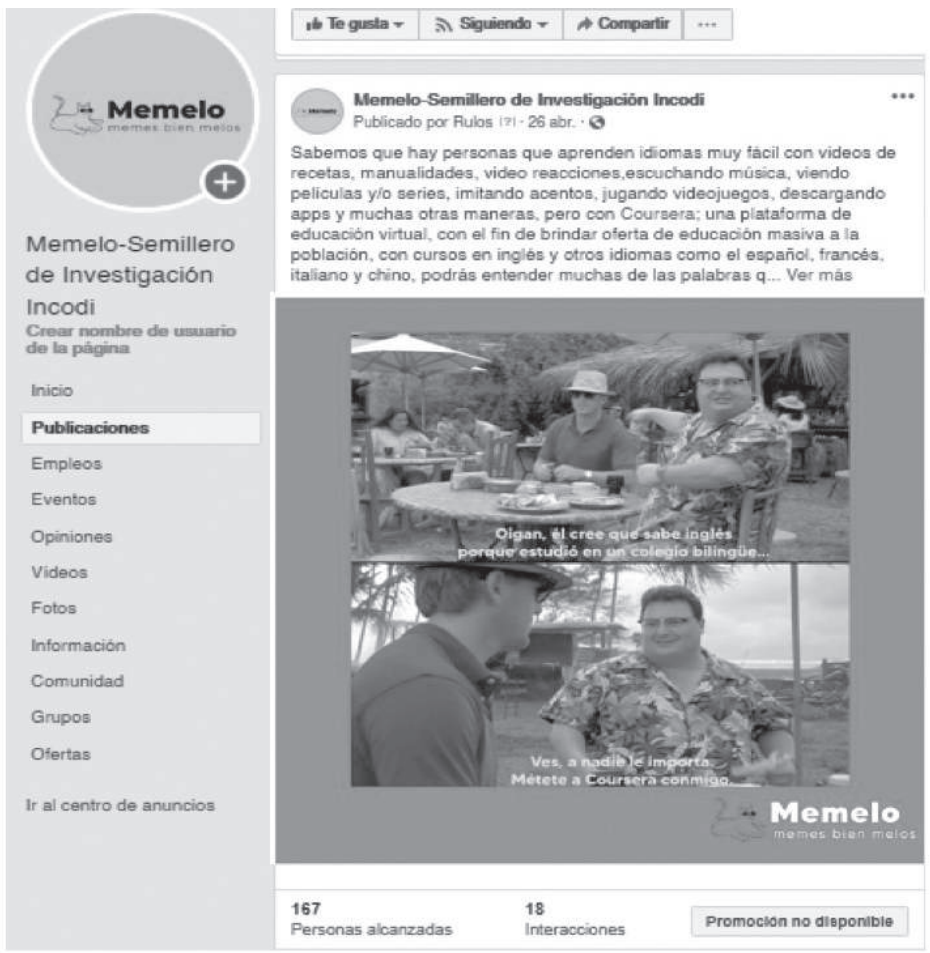

Figura 5. Meme elaborado por el semillero de investigación INCODI.

Facebook.

Con la información que nos arrojó este grupo focal, entendimos parcialmente la dinámica de los jóvenes en relación con las redes sociales y el meme dentro de ellas; y es que esto ha sido una revolución para ellos. Todo el día están viendo memes, compartiendo y creando, se ha convertido en un tema de conversación $y$ de alguna manera se debe tener contexto de las imágenes/vídeos/textos para hablar sobre ellos. Son nuevas formas de comunicación a las que de alguna manera se fueron adaptando. ${ }^{10}$

Con todo esto, demostramos que además de generar un interés por la investigación de los memes, debemos cultivar y/o realizar una iniciativa desde los primeros semestres de la carrera, buscar más allá de lo que vemos, saber de dónde y cómo vienen los contenidos que utilizamos, ir a lo más profundo de cada tema abordado.

\footnotetext{
${ }^{10}$ Para finalizar, debemos como futuros comunicadores audiovisuales, saber de dónde viene lo que utilizamos, ser conscientes en lo posible de cuáles son las cosas que mueven al mundo y así poder trabajar con ellas, tener astucia y saber manipular o manejar la información para poder vender.
} 


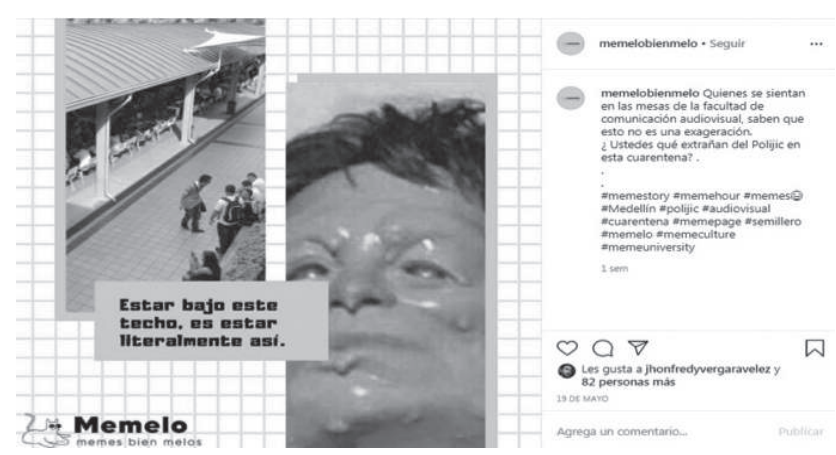

Figura 6. Meme elaborado por el semillero de investigación INCODI. Instagram.

Por último, es complaciente saber que, en el grupo focal, "implantamos" la idea de hacer lo anteriormente mencionado, saber que logramos crear una posición crítica frente al meme, su historia, el internet y toda su evolución; incluso, especular cómo podría seguir evolucionando.

\section{Conclusiones}

Las prácticas comunicacionales de estos jóvenes, están articuladas a los usos y consumos de las informaciones que toman de los medios masivos de comunicación y también de las que se difunden y se multiplican en internet y en todas las redes sociales, pero dichas prácticas, desde luego, se sitúan en los hábitos, actuaciones y en las posibilidades de re-crear y producir contenidos derivados de otros existentes.

La versatilidad en los formatos y narrativas de los mensajes en las redes sociales y plataformas digitales no resulta en un intento de cosificación de la comunicación, sino que permite verdaderamente comprender que existe una comunicación como proceso de encuentro e intercambio de sentidos y significaciones diversas, ancladas a las lógicas del gusto, el disfrute y la expresión propia de estos jóvenes, de acuerdo a sus intereses y motivaciones particulares y colectivas.

También en esta dimensión, la comunicación vista y vivida por ellos, desde la lógica de las tecnologías digitales, ha presupuesto la conversión y configuración de los roles de los actores comunicativos. Para Kaplún (1998) esto constituye que los " $(\ldots)$ receptores se tornan más autónomos en la medida en que ellos mismos ejercen y practican el acto emisor" (p.221). ${ }^{11}$

\footnotetext{
11 "Yo digo que cuando una persona normal así como nosotros sube videos a internet, también ayuda a que otras personas vean el pensamiento de uno" (fuente estudiante grupo focal).
} 


\section{Contexto vegara, a, y conaes,}

Sin embargo, dichas prácticas comunicacionales están acompañadas por un marcado uso y consumo de contenidos e informaciones de variados formatos, estilos y discursos afines a los intereses y motivaciones de estos jóvenes. Las gratificaciones no solamente se evidencian desde impulsos primarios emocionales, sino que permiten generar otras lecturas y significaciones de la realidad. ${ }^{12}$

En efecto, estos jóvenes en su condición de actores comunicativos, se encuentran construyendo procesos comunicacionales, desde el rol del emisor, pero circulando de manera continua en recepciones activas enmarcadas en los usos y consumos de la información; claro está, siendo audiencias de la oferta de contenidos de los medios de comunicación masivos y los formatos, estilos y narrativas audiovisuales digitales, pero transitando hacia los roles activos de la producción y re-producción del mensaje que posibilitan las redes sociales y la comunicación digital. Y precisamente bajo este paradigma comunicacional-digital en el que están inmersos estos jóvenes, y que les permite transitar y configurar sus roles en sus actos comunicativos, que evidencian la incorporación de ideas y gustos, en función de sus subjetividades y en la constitución como sujetos-jóvenes. En esencia, el dominio de las destrezas comunicativas, la posesión y apropiación de los signos y la capacidad de expresar y comunicar, es lo que puede denominarse como competencia comunicativa (Kaplún, 1998, p.238).

Por ello, es imprescindible comprender que las dinámicas de inserción de las nuevas herramientas digitales determinan las prácticas culturales juveniles y educativas. La innovación tecnológica obliga a desarrollar unas competencias en lenguaje para habitar el mundo en el que perseveran con mayor medida los intereses particulares de estos jóvenes en condición de sujetos juveniles y sujetos-educandos. La información preestablecida (currículo) a veces no concuerda con la búsqueda vocacional e informacional de ellos. Esta reflexión surge en la medida que se profundiza lo expuesto por Pisciteli (2001): desde entonces, esta nueva tecnología modificó progresivamente su perfil -yendo siempre en dirección al "mejoramiento" y la profundización de la capacidad de expresión estética- gracias al aumento de la velocidad de procesamiento y almacenamiento, diseño de interfaces "amistosas" con el usuario, gráficos de alta resolución, sonido estereofónico, impresoras láser a color, lenguajes de programación de alto nivel y una notable cantidad de dispositivos de hardware útiles para el artista, tales como lápices gráficos, scanners y sintetizadores.

\footnotetext{
12 "Por ejemplo en Youtube, hay un canal donde también generan información sobre las cosas que pasan en Colombia, pero no lo hacen en forma de noticias, simplemente generan la información y la dan, ique la persona la tome como quiera!, sino que también lo expresan de forma bizarra, expresan la comunicación de una forma más dinámica, que uno capte la intención del que está haciendo la noticia al que le está llegando" (fuente estudiante grupo focal)".
} 
Por ende, el abordaje del proceso comunicativo de estos jóvenes-estudiantes adquiere gran importancia, en tanto que sus dinámicas creativo-comunicativas estén en consonancia con la producción de la cultura y las interacciones sociales, emocionales y afectivas que establecen los jóvenes en contextos y escenarios diversos. En este sentido, para Kaplún (1998) la producción de las dinámicas comunicativas de estos chicos y chicas se inscriben dentro del paradigma de la reciprocidad que resignifica, no solo la acción de comunicar, sino que coloca en el espacio de las relaciones intersubjetivas de las juventudes, las configuraciones del lenguaje en sus formas materiales y manifestaciones abstractas que implican ahora, y para los jóvenes particularmente, la comunicación; y es "gracias al permanente ejercicio del lenguaje en el espacio social como el ser humano interioriza esos símbolos culturalmente elaborados -palabras- que le hacen posible a la vez comunicarse y representar los objetos, vale decir, pensar" (Kaplún, 1998, p.233).

La comunicación que producen los estudiantes, entonces, plantea la acción y movimiento de los sujetos juveniles a través de la consolidación de hábitos y prácticas en y desde las actividades comunicativas, que interpelan a la constitución de un sujeto-comunicativo que se significa a sí mismo y al otro desde los códigos lingüísticos, los instrumentos empleados y los vehículos de la comunicación; en correspondencia a las cosmogonías sociales, culturales, emocionales y afectivas de sus existencias como sujetos juveniles y ante todo desde sus propias cosmovisiones del mundo.

Frente a los procesos de construcción de las subjetividades de estos jóvenes, sus prácticas comunicacionales son determinantes, en la medida en que logran articular, tanto sus interacciones sociales, así como las significaciones de sus identidades propias y, desde luego, en las configuraciones de sus roles y actuaciones socioculturales, en el contexto de los usos y consumos de los medios de comunicación, las tecnologías digitales y las redes sociales.

\section{Referencias}

Beriain, J. (1996). Las consecuencias perversas de la modernidad. Barcelona, España: Anthropos.

Bourdieu, P. (1990). Sociología y cultura. México: Grijalbo.

Gómez, I. (2013-2014). Del meme al imeme, trascendiendo la dimensión lúdica. Entretextos, 5(15), 1-9.

González, F. (2017). Uso de memes como mediadores de las vivencias de estudiantes universitarios. En F. González (Presidencia). Investigación Educativa. Simposio llevado a cabo en el Congreso Nacional de Investigación Educativa COMEI, San Luís de Potosí, México. 


\section{Contexto vergasa, y corras,}

Habermas, J. (1987). Teoría de la acción comunicativa. Madrid, España: Taurus.

Kaplún, M. (1998). Una pedagogía de la comunicación. Madrid, España: Ediciones De la Torre.

Martín-Barbero, J. (1992). Pensar la sociedad desde la comunicación: un lugar estratégico para el debate a la modernidad. Diálogos De La Comunicación, 32, 1-5.

Memelo-Semillero de Investigación Incodi. Fotos de biografía [Álbum de fotos]. Recuperado de https://web.facebook.com/Memelo-Semillero-deInvestigaci\%C3\%B3n-Incodi-108598963960492/

Memelo-Semillero de Investigación Incodi. Fotos de biografía [Álbum de fotos]. Recuperado de https://www.instagram.com/p/CAYD1HfDI9w/

Muñoz, G. (2008). El consumo juvenil en la sociedad mediática. Comunicação, mídia e consumo, 5, 57-75.

Pisciteli, A. (2001). Ciberculturas 2.0 en la era de las maquinas inteligentes. Buenos Aires, Argentina: Paidós.

Santibáñez, C. (2001). Teoría Social y Memes. A Parte Rei, 18, 1-9.

Urresti, M., Linne, J. y Basile, D. (2015). Conexión total: los jóvenes y la experiencia social en la era de la comunicación digital. Buenos Aires, Argentina: Grupo Editor Universitario, CLACSO.

\section{Para citar este artículo:}

Vergara, J. y Correa, J. (2020). El meme como práctica, expresión y manifestación artística, cultural y comunicacional de los jóvenes en la actualidad, caso Facultad de Comunicación Audiovisual del Politécnico Colombiano Jaime Isaza Cadavid. En-Contexto, $8(12), 155-174$. 